This is the author's final, peer-reviewed manuscript as accepted for publication. The publisher-formatted version may be available through the publisher's web site or your institution's library.

\title{
An examination of the broaden-and-build model of positive emotions in military marriages: an actor-partner analysis
}

Joyce A. Baptist and Briana S. Nelson Goff

\section{How to cite this manuscript}

If you make reference to this version of the manuscript, use the following information:

Baptist, J. A., \& Goff, B. S. N. (2012). An examination of the broaden-and-build model of positive emotions in military marriages: An actor-partner analysis. Retrieved from http://krex.ksu.edu

\section{Published Version Information}

Citation: Baptist, J. A., \& Goff, B. S. N. (2012). An examination of the broaden-andbuild model of positive emotions in military marriages: An actor-partner analysis. Journal of Couple \& Relationship Therapy: Innovations in Clinical and Educational Interventions, 11(3), 205-220.

Copyright: Copyright $\odot$ Taylor \& Francis Group, LLC

Digital Object Identifier (DOI): doi:10.1080/15332691.2012.692942

Publisher's Link: http://www.tandfonline.com/doi/full/10.1080/15332691.2012.692942

This item was retrieved from the K-State Research Exchange (K-REx), the institutional repository of Kansas State University. K-REx is available at http://krex.ksu.edu 
In-press in the Journal of Couple and Relationship Therapy

\author{
An Examination of the Broaden-and-Build Model of Positive Emotions in Military Marriages: An \\ Actor-Partner Analysis \\ Joyce A. Baptist ${ }^{1}$ and Briana S. Nelson Goff ${ }^{2}$ \\ School of Family Studies and Human Services \\ Kansas State University, Manhattan, KS
}

\begin{abstract}
How emotional and cognitive processes combined to produce resilience in military marriages post-combat deployments was examined using the "broaden-and-build model of positive emotions" with 40 military couples. The model suggests that positive emotions expand, and negative emotions impede cognitive processes. Utilizing the Actor-Partner Interdependence Model, the association between positive and negative emotions on insight-causation was examined. Actor and partner effects were found for service members' positive emotions and spouses' negative emotions but not service members' negative emotions and spouses' positive emotions. Service members' actor and partner effects were significantly stronger than spouses.' Clinical and research implications are discussed.
\end{abstract}

Key Words: military deployments, dyadic analysis, broaden-and-build, positive emotions

Support for this research was provided by funding from a Kansas State University Small Research Grant and the Kansas State University College of Human Ecology SRO Grant.

${ }^{1}$ Corresponding author, School of Family Studies and Human Services, Family Kansas State University, FSHS, 302 Justin Hall, Manhattan, KS 66506; Phone: 785-532-6891; Fax: 785-532-6523; E-mail: jbaptist@ksu.edu. ${ }^{2}$ College of Human Ecology, Kansas State University, FSHS, 302 Justin Hall, Manhattan, KS 66506.

“...when you get back you're so thankful (for) the things that you have, and you realize what you have, and the things you missed and...I try to put extra effort on family versus work...” noted a service member after his return from Iraq.

The stressful life of military families has been widely documented - from extended separation and multiple relocations to bearing witness to mass destruction and suffering. It is not surprising then that the overall demands and stress experienced by military families that can lead to chronic impairment of service members and disrupt marital and family relationships have been the main focus of research. In particular, the deployments of U.S. service members to the wars in Iraq and Afghanistan that comprise the longest armed conflict of the U.S. military since the end of the draft (Sammons \& Batten, 2008) have garnered considerable attention in the literature. Researchers though have overemphasized the negative outcomes of combat-related deployments on service members overlooking the resilient nature of military families (e.g., Waysman, Mikulincer, Solomon, \& Weisenberg, 1993). Although divorce rates in the military have risen from $2.6 \%$ in 2001 when the U.S. began sending troops to Afghanistan in response to the September 11 terrorist attacks to 3.6\% in 2009, the divorce rates are somewhat similar to the provisional national divorce rate of 3.4\% in 2009 (Center for Disease Control and Prevention, 2010). Military marriages that remain intact have received little if any attention in the literature.

What has helped military couples endure and persevere through the multiple stressors of military life is not well understood. More specifically, theory-driven models that help explain how the processes of resilience play out when adapting to distress are needed (Wadsworth, 2010). Understanding military couples' adaptive processes can provide the foundation for programs that promote effective adaptation and facilitate the development of treatment interventions for marriages that are adversely affected by deployment (Karney \& Crown, 2007). We designed this study to gain a better understanding of how emotional and cognitive processes combine to produce resilience in marriages that have persevered through combat-related deployments. We conceptualized a model for understanding the adaptation process of military couples based on the "broaden-and-build model of positive emotions" (Fredrickson, 2000). The model proposes that positive emotions predict the broadening of cognitive processes that subsequently expand an individual's ability to cope with stressors. Using data from military couples who experienced Operation Iraqi Freedom (OIF)/Operation Enduring Freedom (OEF) deployments we tested the broaden-and-build model of positive emotions. The Actor-Partner Interdependence Model (APIM) was further applied to examine interdependence in military marriages.

The Broadening Effects of Positive Emotions

In her broaden-and-build model of positive emotions, Fredrickson (2000) asserted that negative emotions such as fear, anger and sadness, limit immediate thought-action repertoire that truncate the ability to cope effectively 
with stress. Positive emotions such as joy, interest and contentment, on the other hand, broaden immediate thoughtaction repertoire prompting a wider range of thoughts and actions such as explore and seek. Positive emotions are further believed to have the capacity to down-regulate the lingering effects of negative emotions. In fact studies found that positive emotions undid the health-damaging cardiovascular reactivity that lingered following negative emotions (e.g., Fredrickson \& Levenson, 1998).

The broadening of thought-action repertoire of positive emotions can in turn improve the ability to look beyond immediate stressors and adopt a broader perspective that can then help generate a larger array of problem solving solutions (Fredrickson, 2000). This multiplicative capacity is said to be a hallmark of resilient persons that helps them broaden their behavioral repertoire, redefine their beliefs (Mancini \& Bonanno, 2006), and increase the likelihood of finding positive meaning in future events (Fredrickson, 2001). The final product of thought-action repertoire broadening is the building of enduring resources that serve as reserves to be drawn on later to manage future threats (for detail reviews see Fredrickson, 2001).

Fredrickson's model, supported by extensive research, suggests that positive affect increases a person's ability to accept multiple views on an issue and to access alternative cognitive perspectives (see Ashby, Isen, \& Turken, 1999 for a review of the research) such as gaining insight and causal thinking. Gaining insight refers to the process of self-reflection while causal thinking refers to the process of seeking reasons to explain cause and effect that facilitate understanding and meaning making. The use of causal and insight words to describe a past event can suggest the active process of reappraisal. Studies found that increased use of causal (e.g., because, effect) and insight (e.g., realize, understand) words predicted recovery from trauma (Pennebaker, Mehl, \& Niederhoffer, 2003). Casual and insight words were associated with seeking explanations that when combined with discussion of traumatic events has resulted in the best health outcomes (Kross \& Ayduk, 2008). Studies also found that causal words that were used in the most traumatic parts of relationship breakup were used to create causal explanations to organize thoughts (Boals \& Klein, 2005).

Positive affect is further said to increase the ability to combine information in new ways and to notice the connections between differences (Isen, Daubman, \& Nowicki, 1987). This increased cognitive flexibility is believed to lead to new ways of problem solving that build resilience. It was suggested that because positive emotions can increase resilience, positive emotions allow persons to develop resources that help them deal with life challenges that in turn lead to life satisfaction (Cohn, Fredrickson, Brown, Mikels, \& Conway, 2009). Research supports the claim that psychological resilience is associated with positive emotions especially during stressful times (e.g., Ong, Bergeman, Bisconti, \& Wallace, 2006).

Similar findings were reported with enduring relationships such as marriages. Happy couples interact in more random, unpredictable ways, consistent with the broadening effects of positive emotions (Gottman, 1999). In contrast, the interactions of unhappy couples are predictable, structured and rigid. Gottman suggested that happy, stable couples build an "emotional bank account” of positive sentiments for their partners and their marriages that function as a resource during conflict. Such stable couples were more likely to de-escalate negative affect during conflicts (Gottman, 1999) making them more resilient to stress.

\section{Military Marriages}

Military marriages have to adapt to the changing demands of military life and many have effectively rebounded from psychological and behavioral perturbations from critical incidents such as deployments to combat zones, multiple relocations, and separations making them resilient (Kaminsky, McCabe, Langlieb, \& Everly, 2007). Service members and spouses were found to frequently cite personal growth, career advancement and increased income as positive aspects of the deployment experience (e.g., Newby, McCarroll, Ursano, Fan, Shigemura, \& Tucker-Harris, 2005). Studies on deployment and military marriages have however not explored the resilient nature of military couples. More specifically, the main concepts within the broaden-and-build model of positive emotions -positive emotions and cognitive processes -- have not been applied to military couples.

Studies on emotions have primarily focused on negative emotions. For instance, separation due to war was found to contribute to anxiety, anger, depression, loneliness and emotional detachment (Vormbrock, 1993). Anger and combat exposure were found to increase violence and unlawful/antisocial behavior and stress, which in turn, adversely affected marital quality and stability among Vietnam veterans (Gimbel \& Booth, 1994). More anger and partner abuse were also found among combat veterans with posttraumatic stress symptoms (e.g., Sherman, Sautter, Jackson, Lyons, \& Han, 2006). In addition, emotional numbing or a deficit in experience and/or expression of positive emotion (Litz, 1992) experienced by traumatized individuals were found to contribute to relationship difficulties (Riggs, Byrne, Weathers, \& Litz, 1998). Negative emotions have received the most attention in the literature on deployment while positive emotions have received little to no attention.

Studies on the effects of deployment on cognitive processes have primarily focused on perceptions and dissociation. For instance, spouses of service members were found to experience greater psychological and marital 
distress when they perceived substantial PTSD symptoms in their service member, but service members failed to endorse such problems (Renshaw, Rodrigues, \& Jones, 2008), inferring that partners’ perceptions might have a greater effect on marital satisfaction than the service members' symptom severity. For service members deployed during OIF/OEF, dissociation, a cognitive process, predicted lower marital satisfaction in partners and service members (Nelson Goff, Crow, Reisbig, \& Hamilton, 2007). In this study we focused on two cognitive processes -insight and causation -- and examined the extent positive and negative emotions were associated with insight and causal thinking related to deployment.

\section{Interdependence in Marriages}

The interdependent nature of couple relationships provides the basis for individuals' emotion, cognition or behavior to affect the emotion, cognition or behavior of their partners (e.g., Kelley \& Thibaut, 1978). The stronger the level of dependence, the more intertwined are individuals with their partners and the more influence partners have on individuals' thoughts, emotions and behaviors. Thus, to fully comprehend human behavior it is necessary to understand the nature and meaning of interpersonal interdependence. Methodologically, relational interdependence suggests the need to examine mutuality between partners (Kenny, 1996). Consequently, in addition to considering the degree individuals' independent variable score is associated with their own dependent variable score (known as actor effects), there is the need to consider the degree individuals' independent variable score is associated with their partners' dependent variable score (known as partner effects).

APIM was designed by Kashy and colleagues (e.g., Kashy \& Kenny, 2000) to test simultaneous and independent modeling of actor and partner effects. The APIM framework considers the dyad as the unit of analysis where the dyads are nonindependent such as in this study with married couples. The model that guided this study is illustrated in Figure 1. In light of Fredrickson's (2000) broaden-and-build model of positive emotions that positive emotions expand while negative emotions impede cognitive processes, the actor effects are depicted in the paths from an individual's own emotional state (positive and negative) to his/her own cognitive process (insightcausation). The partner effects are depicted in paths from an individual's own emotional state to his/her partner's cognitive process. This approach recognizes that the couple is an interdependent system with the potential to be mutually dependent -- emotionally and cognitively. Another advantage of APIM is that associations between variables are estimated while simultaneously controlling for other associations in the model (Kenny, 1996). Applying the APIM, we hypothesized that actors' insight-causation would be positively associated with their own positive emotions and negatively associated with their own negative emotions. We further hypothesized that actors' insight-causation would be positively associated with their partners' positive emotions and negatively associated with their partners' negative emotions.

\section{Design and Procedure}

\section{Method}

We utilized a mixed research methodology. We conducted separate face-to-face interviews with service members and spouses to elicit the uncensored stories of how deployment affected military marriages and to understand how the participants made meaning of their deployment experiences. Next, the transcribed interview data was subjected to a detailed text analysis to extract the study variables "positive emotions," "negative emotions," "insight" and "causation" measured by the frequency of the use of words that described the variables. The transcripts were used to verify the meaning of the study variable extracted. The following sentences are examples of positive emotion, negative emotion, insight and causal words (in italics) used. Positive emotion: “...he tries very hard to be very romantic and that's something that changed since he came back." Negative emotion: "I have kids and they have a life and she's the leader of the kids but I'm not really anything.” Insight: “Once I kinda realized that it wasn't his fault that he was gone and that he really wanted to be home, then I kinda chilled out." Causal: "I mean it's nice to be able to be apart for a while, sometimes, because then when you come back you both have new experiences to share...” In addition to interviews, participants completed marital satisfaction and trauma-related measurement instruments.

The sampling method was purposeful and convenient. Criteria for participation included recent OIF/OEF deployment, voluntary participation, age18 years or older, and in their current relationship for at least one year. Participants were recruited from two small cities in the Midwest neighboring two Army posts. One post houses several combat units, while the other is primarily a training facility for majors and lieutenant colonels. Recruitment was via publicly posted flyers and newspaper announcements and referrals from Army Family Readiness Groups, chaplains, and other local military sources. Each of the fifty couples that participated in this study received \$50 for their participation. All couples were married at the time of the interviews.

Participants were interviewed by the Co-Principal Investigator or a doctoral student at a nearby university. Each interview took 45 to 90 minutes to complete. The interview was guided by 30 open-ended questions that focused on the deployment experience, intra- and inter-personal effects of trauma experiences and dyadic 
functioning. Only data from the 8 questions that focused on deployment's effect on couples' dyadic functioning was included in this study. For example: How is your relationship most affected by your/your partner's deployment? How do issues related to your/your partner's deployment arise in your relationship? When has your/your partner's deployment had the most negative effect on your relationship?

Participants completed the 32-item Dyadic Adjustment Scale (DAS; Spanier, 1976) that measures the quality of the relationship as perceived by both partners using a Likert scale. Total scores range from 0 to 151, with higher scores indicating greater marital satisfaction. Persons scoring 100 and below on the DAS scale were classified by Spanier (1976) as relationally distressed; those with scores of 101 and higher were classified as relationally non-distressed. The DAS has demonstrated good internal consistency on the total score (Alpha = .96; Fischer \& Corcoran, 2000). Spanier (1976) provided evidence of the content, criterion-related and construct validity. Reliability alpha for this study was .87. Of the 50 couples, 40 (80\%) couples had both partners scoring within the non-distressed category and 3 (6\%) couples had both partners scoring within the distressed category.

\section{Participants}

Since the purpose of this study was to examine non-distressed military couples, only data from couples where both partners scored 101 or more on the DAS (non-distressed category) were included, i.e., 40 couples/80 persons. In each couple, the service member was male and the partner was female. The DAS scores for service members ranged from 107 to $151(M=125.65 ; S D=11.84)$ and spouses' scores ranged from 109 to $148(M=$ 123.01; $S D=8.24)$. The average length of marriage was 6.05 years $(S D=6.44$, Range $=1$ to 23 years). Their ages ranged from 20 to 51 years $(M=31.60, S D=7.73)$ for service members, and from 19 to $48(M=30.15, S D=7.24)$ for spouses. The majority of participants were White (31 female, 33 male; 80\%). In addition, there were four African Americans (1 female, 3 male), three Mexican Americans (1 female, 2 male), two Asians/Pacific Islanders (both female), six American Indians/Alaskans (4 female, 2 male), and one female who identified as "Other." The overall range of deployment length was 1 to 18 months (first deployment: $M=9.88, S D=3.99$; second deployment: $M=3.50, S D=1.32$ ). Thirty eight (95\%) of the service members were deployed during OIF and two (5\%) during OEF on their first deployments. Four (10\%) service members had experienced a second deployment; three during OIF and one during OEF. The service members had returned from their last deployment for an average of 5.35 months $(S D=3.9$, Range $=1 / 2$ to 16 months $)$.

Text Analysis

The Linguistic Inquiry Word Count (LIWC2007), a text analysis software program was used to analyze the interview data. The LIWC2007 calculates rates of word usage for a range of categories including advanced conceptual categories that tap emotional, cognitive and social processes. LIWC2007 checks each word in the database against its internal dictionary of more than 4,500 words and word stems, and assigns them to specific linguistic categories. LIWC2007 provides the means of the frequency of words used expressed as a percentage of the total words in any given speech/text sample. Larger mean scores denote a higher frequency of word usage.

LIWC2007 has been widely used and extensively validated. Internal reliability of occurrence/nonoccurrence of insight, causation, negative and positive emotion words ranged from .80 to .97 . Details on validity and reliability can be obtained online (LIWC, 2007). The following words were extracted from the interview transcripts using LIWC2007: positive emotion words (e.g., love, joy, beautiful, exciting, pride, certainty), negative emotion words (e.g., sad, anxious, anger, worthless, hate), causal words (e.g., because, reason, effect, cause) and insight words (e.g., realize, think, consider, understand). Insight and causal words were summed together and referred to as "insight-causation." After extracting the frequencies of the use of these words, data was analyzed using SPSS 19 and AMOS 19 (Arbuckle, 2010) for actor and partner effects.

\section{Preliminary Analysis}

\section{Results}

Before exploring actor and partner effects, the statistical power, effect of sex differences on study variables and couple interdependence were examined. The power (Cohen, 1988) of the test of nonindependence for a sample size of 40 dyads, given alpha of .05 for a two-tailed correlation of .486 (of the outcome variable -- insight-causation, after controlling for the predictor variables -- positive and negative emotions) for service members and spouses was .90. Thus a 40 -dyad sample size had a more than $80 \%$ chance of detecting differences at a $95 \%$ confidence level.

Differences between service members and spouses on positive and negative emotions and insight-causation were examined using MANOVAs. Results indicated no overall main effects for sex, Wilks' Lambda $=.995, F(3,76)$ $=.133, p=.940$ suggesting that service members and spouses did not differ in their use of positive and negative emotions and insight and causation words when describing their deployment experience. The couples appeared to utilize similar amounts of words to appraise their deployment experience using self-reflection and creating causal explanations. Although couples did not differ in their use of positive and negative emotion words, both service members and spouses used more positive emotion words ( $M=3.46$ and 3.54 respectively) compared to negative 
emotion words ( $M=1.56$ and 1.51 respectively) when recalling their deployment experience. The couples appeared to have more positive than negative sentiment about their deployment experience.

To verify interdependence among service members and their spouses, Bivariate Pearson correlations of positive and negative emotions and insight-causation were computed and presented in Table 1. Insight-causation was positively related to positive emotion for service members $(r=.39, p=.013)$, and negatively related to negative emotion for spouses $(r=-.31, p=.048)$. More importantly, cross-partner correlations indicated interdependence between service members' and spouses' insight-causation $(r=.60, p<.01)$ and positive emotion $(r=.39, p=.012)$, and service members' positive emotions and spouses insight-causation $(r=.54, p<.001)$. Results suggested that positive emotions were strongly associated with cognitive processes for both service members and their spouses while negative emotions were strongly associated with cognitive processes for spouses.

\section{Actor and Partner Effects}

The two central components of APIM (actor and partner effects) were tested using structural equation modeling with a maximum likelihood estimator. To control for the nonindependence of partners' scores, the positive and negative emotion scores for service members' and spouses' were allowed to correlate, as were the two error terms for service members' and spouses' insight-causation. There were no latent variables in the model that was saturated or just-identified. The model fit the data perfectly and had a chi-square and $d f$ of zero (Kenny, 1996). Actor and partner effects of positive and negative emotions on insight-causation are shown in Figure 1.

To further explore possible differences in the strengths of service members' and spouses' actor effects, we compared two models - one with the actors' path coefficients unconstrained and one with the actors' path coefficients constrained. A significant difference between models would indicate differences in service members' and spouses' actor effects. A similar process was used to test differences in partner effects.

Actor effects. Actor effects were partially supported. Service members' positive emotions were positively associated with their own insight-causation (Beta $=.74, p=.009$ ), while their negative emotions were not significantly related to their own insight-causation (Beta $=-.69, p=.095$ ). Spouses' negative emotions were negatively associated with their own insight-causation (Beta $=-.95, p=.011$ ), while their positive emotions were not significantly related to their own insight-causation (Beta $=.07, p=.758$ ). The comparison of actor effects for service members and spouses found differences in the strength of effects, $x^{2}(2)=134.05, p<.001$. Service members' actor effects $\left(R^{2}=33 \%\right)$ were significantly stronger compared to spouses' $\left(R^{2}=16 \%\right)$.

Partner effects. Partner effects were partially supported. Service members' positive emotions were positively associated with spouses' insight-causation (Beta $=.98, p<.001$ ), while their negative emotions were not significantly related with spouses' insight-causation (Beta $=.17, p=.650$ ). Spouses' negative emotions were negatively associated with service members' insight-causation (Beta $=.93, p=.029$ ), while their positive emotions were not significantly related to service members' insight-causation (Beta $=-.09, p=.720$ ). The comparison of partner effects for service members and spouses found differences in the strength of effects, $x^{2}(2)=128.12, p<.001$. Service members' partner effects $\left(R^{2}=69 \%\right)$ were significantly stronger compared to spouses' $\left(R^{2}=12 \%\right)$.

The combined actor and partner effects accounted for $28 \%$ of the variance in service members' insightcausation and $40 \%$ in spouses' insight-causation. Results indicated that emotional levels were more strongly associated with the use of insight and causation for spouses than for service members.

\section{Discussion}

The broaden-and-build model of positive emotions (Fredrickson, 2000) was used to understand how emotional and cognitive processes combined to produce resilience in marriages that have persevered through combat-related deployments. For service members, results suggested that cognitive processes -- insight and causation -- were positively related to their own levels of positive emotions and negatively related to their spouses' level of negative emotions. For spouses, results suggested the opposite. Spouses' process of gaining insight and seeking explanations were negatively related to their own levels of negative emotions and positively related to service members' positive emotions. Results supported the broaden-and-build model of positive emotions in that positive emotions expanded cognitive processes while negative emotions impeded cognitive processes. However, only service members' positive emotions and only spouses' negative emotions were significant predictors of insight and causation. The results suggested that during stressful times such as deployment, service members' but not spouses' ability to reframe their experience in a positive light was important in building resilience and helping couples cope with their experience. Conversely, spouses' negative feelings about the deployment experience were more likely to impede resilience building compared to service members' negative feelings.

Overall, results suggested that for service members, positive emotions might have buffered the effects of deployment stress and negative emotions allowing service members to make meaning of their deployment experience. Results supported previous studies where improvements in mental and physical well-being were found to be related to reflecting on traumatic events with the intention of dealing with its effects (e.g., Pennebaker, 
Maynes, \& Francis, 1997). Service members' ability to offset negative emotions and deployment stress with positive emotions could reflect their levels of resilience. This process could be impeded by their spouses' negative sentiments about the deployment experience although unlikely considering that spouses' partner effects explained only $12 \%$ of service members' insight-causation compared to service members' own actor effects that explained $33 \%$ of their own insight-causation.

Results further suggested that spouses' own positive reactions to deployment were insufficient to buffer the effects of their own negative experiences of deployment. In fact, spouses' process of coping with deployment appeared to be more dependent on service members' having had experienced deployment as positive that outweighed spouses' own sentiments about deployment. Service members' partner effects explained $69 \%$ of spouses' insight-causation compared to spouses' own actor effects that explained $12 \%$ of their own insightcausation. Results implied that spouses could be more in-tuned and concerned about how service members coped with their deployment experience thus prioritizing service members' needs over their own.

Interestingly, service members' emotional reactions were more strongly related to the couples' ability to make meaning of their deployment experience compared to spouses' emotional reactions. Service members appeared to be more adept compared to spouses at drawing on positive emotions to their advantage. This finding supported previous studies that found men to recover more quickly from negative emotional stimuli compared to women (Fredrickson \& Levenson, 1998). The authors attributed the findings to men's greater sensitivity to physiological activation (e.g., Roberts \& Pennebaker, 1995) that in turn helps them to rebound more quickly, thus disallowing negative emotions to control their lives. Women on the other hand were said to be more likely than men to ruminate about the reasons and consequences of their own distress (e.g. Nolen-Hoeksema, Morrow, \& Fredrickson, 1993). It is however possible that the service members in this study could have felt a need to overcome their negative experiences in order to help their spouses cope with deployment and reintegration and to be functional at work. Peer support from their battalions and their relief to be home and alive could have been sufficient to help service members recover from the stress of deployment. Although spouses experienced a similar level of positive sentiments as did service members, reintegration post-deployment might not have significantly changed their situation allowing their negative sentiments about deployment to linger on. Furthermore, spouses' anticipation and fear of future deployments could have impeded the use of positive emotions to undo the effects of their negative emotions (Fredrickson \& Levenson, 1998).

Strengths

This study recognizes that military marriages are resilient to stressors such as deployment. The examination of how emotional and cognitive processes interrelate provides insight into the interdependence within enduring military marriages that have been able to adapt to the demands of military life. The research design that elicited the stories of service members and their spouses through separate interviews provided participants the opportunity to disclose information that they might not have disclosed in the presence of their partners.

\section{Limitations}

This study could have been improved with a larger and more random sample of service members and spouses. Recruiting volunteers from two military installations that were selected due to geographic convenience limited the sample to a self-selected group. Female service members were also not represented in the sample despite active recruiting efforts. Participants were recruited from a non-clinical sample, thus it is unknown if the participants were diagnosed with any pre-existing disorders as a result of their deployment or other experiences. Finally, this study could have been improved with a comparison group of distressed couples.

\section{Research and Clinical Implications}

Future research on combat-related trauma and military couples should further investigate the adaptive processes leading to resilience post-deployment. An important topic is the process by which emotions and insightcausal thinking build resilience and help buffer deployment stress. Similar studies comparing non-distressed and distressed couples could more thoroughly examine Fredrickson's broaden-and-build model. How sex differences impact the relationship between emotions and cognitive processes deserves further empirical attention.

The results support the use of interventions that build coping mechanisms, such as sharing positive feelings and using cognitive approaches that focus on gaining insight and seeking explanations. It has been noted that intervention strategies that cultivate positive emotions are well-suited for preventing and treating problems embedded in negative emotions such as anxiety, hopelessness, hostility, and stress-related health problems (Fredrickson, 2000). Cognitive-based interventions, including optimism and positive psychology models that help facilitate the cognitive appraisal of experiences, can improve resilience. Finding positive meaning can help couples cope with the lived experience of deployment, thus strength-based interventions are indicated for couples adversely affected by their deployment experience. A strength-based approach to treatment that focuses on mental health rather than pathology might be more palatable and non-stigmatizing for couples who are reluctant to admit to 
psychological problems and seek treatment.

\section{Conclusion}

The broaden-and-build model of positive emotions provides greater insight into the processes that can build resilience in military marriages. The results suggest that during stressful times such as deployment, service members' but not spouses' ability to reframe their experience in a positive light was important in building resilience. Conversely, spouses' negative feelings about the deployment experience were more likely to impede resilience building compared to service members' negative feelings. Service members' positive sentiments had a larger overall effect on couples' cognitive processes compared to spouses' negative sentiments. Differences in the impact of positive and negative emotions on couples' cognitive processes have implications for practice and warrant further investigation.

\section{References}

Arbuckle, J. L. (2010). AMOS 19 User’s guide. Chicago, IL: SPSS, Inc.

Ashby, F. G., Isen, A. M., \& Turken, A. U. (1999). A neuropsychological theory of positive affect and its influence on cognition. Psychological Review, 106, 529-550.

Boals, A., \& Klein, K. (2005). Word use in emotional narratives about failed romantic relationships and subsequent mental health. Journal of Language and Social Psychology, 24, 252-268.

Center for Disease Control and Prevention (2010, August 27). Births, marriages, divorces, and deaths: Provisions data for 2009. National Vital Statistics Reports, 58(25). Retrieved from http://www.cdc.gov/nchs/data/nvsr/nvsr58/nvsr58_25.htm

Cohen, J. (1988). Statistical power analysis for the behavioral sciences. $\left(2^{\text {nd }}\right.$ ed.). Hillsdale, NJ: Lawrence Erlbaum.

Cohn, M. A., Fredrickson, B. L., Brown, S. L., Mikels, J. A., \& Conway, A. M. (2009). Happiness unpacked: Positive emotions increase life satisfaction by building resilience. Emotion, 9, 361-368.

Fischer, J., \& Corcoran, K. (2000). Measures for clinical practice: A sourcebook: Adults, (2nd ed., Vols. 1-2). New York: The Free Press.

Fredrickson, B. L. (2000). Cultivating positive emotions to optimize health and well-being. Prevention and Treatment, 3, 1-25.

Fredrickson, B. L. (2001). The role of positive emotions in positive psychology: The broaden-and-build theory of positive emotions. American Psychologist, 56, 218-226.

Fredrickson, B. L., \& Levenson, R. W. (1998). Positive emotions speed recovery from cardiovascular sequelae of negative emotions. Cognition and Emotion, 12, 191-220.

Gimbel, C., \& Booth, A. (1994). Why does military combat experience adversely affect marital relations? Journal of Marriage and Family, 56, 391-703.

Gottman, J. M. (1999). The marriage clinic: A scientifically based marital therapy. New York, NY: Norton.

Isen, A. M., Daubman, K. A., \& Nowicki, G. P. (1987). Positive affect facilitates creative problem solving. Journal of Personality and Social Psychology, 52, 1122-1131.

Kaminsky, M., McCabe, O. L., Langlieb, A. M., \& Everly, G. S. (2007). An evidence-informed model of human resistance, resilience, and recovery: The Johns Hopkins' outcome-driven paradigm for disaster mental health services. Brief Treatment and Crisis Intervention, 7, 1-11.

Karney, B. R., \& Crown, J. S. (2007). Families under stress: An assessment of data, theory, and research on marriage and divorce in the military. Santa Monica, CA: RAND National Defense Institute.

Kashy, D. A., \& Kenny, D. A. (2000). The analysis of data from dyads and groups. In H. T. Reis \& C. M. Judd (Eds.), Handbook of research methods in social psychology (pp. 451-477). New York: Cambridge University Press.

Kelley, H. H., \& Thibaut, J. W. (1978). Interpersonal Relations. New York: Wiley.

Kenny, D. A. (1996). Models of interdependence in dyadic research. Journal of Social and Personal Relationships, 13, 279-294.

Kross, E., \& Ayduk, O. (2008). Facilitating adaptive emotional analysis: Distinguishing distanced-analysis of depressive experiences from immersed-analysis and distraction. Personality and Social Psychology Bulletin, 34, 924-938.

Litz, B. T. (1992). Emotional numbing in combat-related post-traumatic stress disorder: A critical review and reformulation. Clinical Psychology Review, 12, 417-432.

LIWC (2007). LIWC2007 Output Variable Information. The LIWC2007 application. Retrieved from http://www.liwc.net/descriptiontable1.php 
Mancini, A. D., \& Bonanno, G. A. (2006). Resilience in the face of potential trauma: Clinical practices and illustrations. Journal of Clinical Psychology, 62, 971-985.

Nelson Goff, B. S., Crow, J. R., Reisbig, A. M. J., \& Hamilton, S. (2007). The impact of person trauma symptoms of deployed service members on relationship satisfaction. Journal of Family Psychology, 21, 344-353.

Newby, J. H., McCarroll, J. E., Ursano, R. J., Fan, Z., Shigemura, J., \& Tucker-Harris, Y. (2005). Positive and negative consequences of a military deployment. Military Medicine, 170, 815-819.

Nolen-Hoeksema, S., Morrow, J., \& Fredrickson, B. (1993). Response styles and the duration of episodes of depressed mood. Journal of Abnormal Psychology, 102, $20-28$.

Ong, A. D., Bergeman, C. S., Bisconti, T. L., \& Wallace, K. A. (2006). Psychological resilience, positive emotions, and successful adaptation to stress in later life. Journal of Personality and Social Psychology, 91, 730-749.

Pennebaker, J. W., Maynes, T. J., \& Francis, M. E. (1997). Linguistic predictors of adaptive bereavement. Journal of Personality and Social Psychology, 72, 863-871.

Pennebaker, J. W., Mehl, M. R., \& Niederhoffer, K. G. (2003). Psychological aspects of natural language use: Our words, our selves. Annual Review of Psychology, 54, 547-577.

Renshaw, K. D., Rodrigues, C. S., \& Jones, D. H. (2008). Psychological symptoms and marital satisfaction in spouses of Operation Iraqi Freedom veterans: Relationships with spouses' perceptions of veterans' experiences and symptoms. Journal of Family Psychology, 22, 586-594.

Riggs, D. S., Byrne, C. A., Weathers, F. W., \& Litz, B. T. (1998). The quality of the intimate relationships of male Vietnam veterans: Problems associated with posttraumatic stress disorder. Journal of Traumatic Stress, 11, 87-101.

Roberts, T., \& Pennebaker, J.W. (1995). Gender differences in perceiving internal state: Towards a his and hers model of perceptual cue use. In L. Berkowitz (Ed.), Advances in experimental social psychology, 27, 143175.

Sammons, M T., \& Batten, S. V. (2008). Psychological services for returning veterans and their families: Evolving conceptualizations of the sequelae of war-zone experiences. Journal of Clinical Psychology, 64, 921-927.

Sherman, M. D., Sautter, F., Jackson, M. H., Lyons, J. A., \& Han, X. (2006). Domestic violence in veterans with posttraumatic stress disorder who seek couples therapy. Journal of Marital and Family Therapy, 32, 479490.

Spanier, G. B. (1976). Measuring dyadic adjustment: New scales for assessing the quality of marriage and similar dyads. Journal of Marriage and the Family, 38, 15-28.

Vormbrock, J. K. (1993). Attachment theory as applied to wartime and job-related marital separation. Psychological Bulletin, 114, 122-144.

Wadsworth, S. M. M. (2010). Family risks and resilience in the context of war and terrorism. Journal of Marriage and Family, 72, 537-556.

Waysman, M., Mikulincer M., Solomon, Z., \& Weisenberg, M. (1993). Secondary traumatization among wives of posttraumatic combat veterans: A family typology. Journal of Family Psychology, 7, 104-118. 


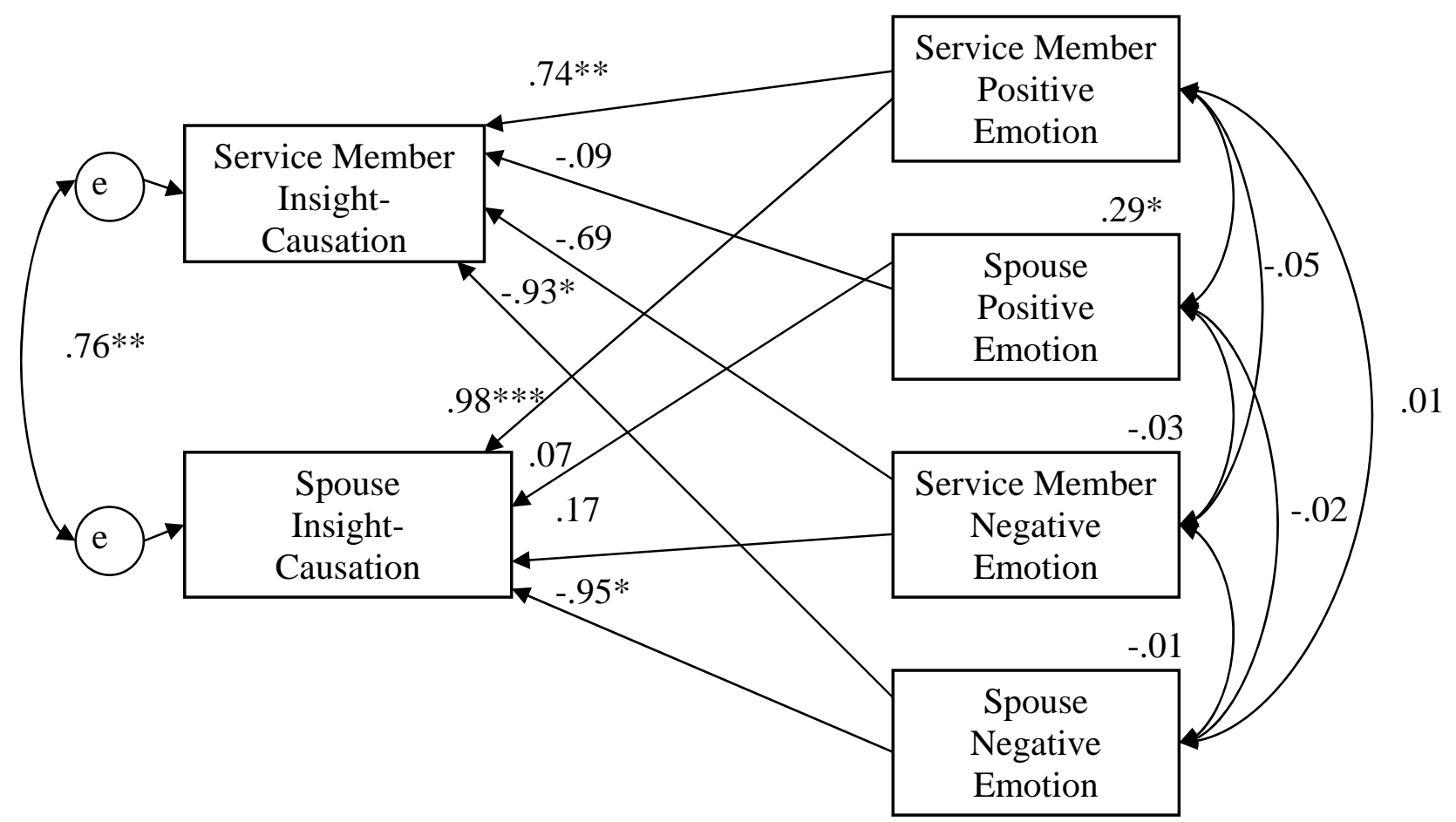

Figure 1. Structural Model Used to Test the Actor and Partner Effects of Positive and Negative Emotions on InsightCausation.

${ }^{*} p<.05$. $* * p<.01 . * * * p<.001$.

Note: Values are the unstandardized coefficients and covariances. 
Table 1. Correlations, Means, and Standard Deviations for Insight-Causation, Positive and Negative Emotions for Service Members (SM) and Spouses (S).

\begin{tabular}{lcccccc}
\hline \multicolumn{1}{c}{ Measure } & 1 & 2 & 3 & 4 & 5 & 6 \\
\hline 1. SM Insight- & - & & & & & \\
$\quad \begin{array}{l}\text { Causation } \\
\text { 2. S Insight- }\end{array}$ & $.60^{* *}$ & - & & & & \\
$\quad \begin{array}{l}\text { Causation } \\
\text { 3. SM Positive }\end{array}$ & $.39 *$ & $.54^{* *}$ & - & & & \\
$\quad \begin{array}{l}\text { Emotion } \\
\text { 4. S Positive }\end{array}$ & .12 & .26 & $.39 *$ & - & & \\
$\quad$ Emotion & & & & & & \\
5. SM Negative & -.25 & .01 & -.11 & -.06 & - & \\
Emotion & & & & & & \\
6. S Negative & -.28 & $-.31^{*}$ & .01 & -.04 & -.05 & - \\
Emotion & & & & & & \\
$\quad M$ & 5.98 & 5.95 & 3.46 & 3.54 & 1.56 & 1.51 \\
$\quad$ SD & 1.59 & 1.54 & .84 & .90 & .52 & .52 \\
$\quad$ Range & $2.93-$ & $2.76-$ & $1.87-$ & $2.10-6.51$ & $.55-2.66$ & $.66-$ \\
& 10.46 & 9.88 & 5.35 & & & 2.87 \\
\hline
\end{tabular}

${ }^{*} p<.05 .{ }^{* *} p<.01$. 